\title{
Is There Any Relationship between the Chronicity of Chronic Anal Fissure and Endothelin-1?
}

\author{
Cheong Ho Lim, Hyeon Keun Shin, Wook Ho Kang, Seung Kyu Jeong, Hyung Kyu Yang \\ Department of Coloproctology, Yang Hospital, Seoul, Korea
}

Purpose: Many kinds of substances are produced on vascular endothelial activation. The aim of this study is to confirm an increase in Endothelin-1 (ET-1), the most potent vasoconstrictor, which is produced by endothelial activation, in patients with chronic anal fissure and to infer the relationship between ET-1 and anal fissure chronicity.

Methods: The study groups are divided into three different groups with 30 subjects each. Group 1 is comprised of healthy volunteers, group 2 of chronic anal fissure patients, and Group 3 of patients with higher than 3rd degree hemorrhoids. Blood samples were taken to measure the ET-1 levels in subject's serum and to compare the results with those for the control groups. Results: Among the 90 subjects, 38 were male, and 52 were female. The average age was 36.8. The average ET- 1 level marked $1.47 \pm 0.78 \mathrm{pg} / \mathrm{mL}$ for male subjects and $1.16 \pm 0.47 \mathrm{pg} / \mathrm{mL}$ for female subjects $(\mathrm{P}=0.02)$. The average ET- 1 level in the patient groups is as follow: $1.21 \pm 0.44 \mathrm{pg} / \mathrm{mL}$ in group $1,1.46 \pm 0.83 \mathrm{pg} / \mathrm{mL}$ in group 2 , and $1.20 \pm 0.56 \mathrm{pg} / \mathrm{mL}$ in group $3(\mathrm{P}=$ $0.14)$.

Conclusion: Group 2, the chronic anal fissure patient group, showed a higher ET-1 level than groups 1 and 3, the control group and the hemorrhoid patient group, but this difference had no statistical significance.

Keywords: Chronic anal fissure; Endothelin-1; Chronicity; Ischemia; Endothelium

\section{INTRODUCTION}

Anal fissure refers to a state of laceration in the direction of thelongitudinal axis for the lower anal canal, which spans from the anal verge to the dentate line. Acute anal fissure can be treated in 1-2 weeks, but chronic anal fissure can last 6-8 weeks and can recur often [1]. Although the pathogenesis of chronic anal fissure is not yet certain, as speculative theoretical causes, extreme tension in the internal sphincter, myositis, ischemia, primary disorder of the internal sphincter, and the activation of vascular endothelium can be included [2].

In the past, the vascular endothelium was recognized as simply an

Received: April 20, 2011 Accepted: August 12, 2011

Correspondence to: Cheong Ho Lim, M.D.

Department of Coloproctology, Yang Hospital, 424 Gil-dong, Gangdong-gu, Seoul 134-814, Korea

Tel: +82-2-480-8008, Fax: +82-2-480-8119

E-mail:chlim3164@naver.com

(C) 2011 The Korean Society of Coloproctology

This is an open-access article distributed under the terms of the Creative Commons Attribution NonCommercial License (http://creativecommons.org/licenses/by-nc/3.0) which permits unrestricted noncommercial use, distribution, and reproduction in any medium, provided the original work is properly cited. inert barrier between the blood stream and vascular smooth muscle; however, several studies showed that $[3,4]$ it is now known to be a functionally active structure. The cells that line blood vessels, through numerous stimuli, generate and release numerous substances $[4,5]$, among which Endothelin-1 (ET-1) is known to be the strongest vasoconstrictor and long-reactive substance [4]. ET-1 is generated the most in the endothelium of blood vessels through infection, hypoxia, or physical strength [5]. As the generation of ET-1 increases, arteriosclerotic changes and fiberization increase; due to the increase in the ET-1 concentration within a cell, nitricoxide production is inhibited in the endothelium of blood vessels, eventually vasodilatation is inhibited $[4,5]$.

The authors made one hypothesis. The generation of ET-1 is increased though activation of the endothelium of a blood vessel due to damage in the anal canal in a chronic anal fissure patient even though ET-1 may not be a direct cause of the anal fissure. Based on that hypothesis, this study attempted to investigate the chronicity of anal fissure and its association with ET-1 by quantitatively measuring ET-1 in the serum of chronic anal fissure patients and comparing the results with those of the control group under the assumption that there is an association with the chronicity of anal fissure. 


\section{METHODS}

Study subjects were divided into three groups: group 1 , healthy adult volunteers without a history of anal diseases; group 2, patients with confirmed cases, through anal speculum, of chronic anal fissure among outpatients [1]; group 3, patients with hemorrhoids of Goligher classification 3 or higher and no other anal conditions such as anal fissure or anal fistula; each group had $30 \mathrm{pa}-$ tients. In each group, patients with personal or family history of high blood pressure, cardiovascular disease, obesity (defined as being $10 \%$ over ideal body weight), smoking, diabetes, hyperlipidemia, arthritis, autoimmune disease, systemic inflammatory disease, inflammatory bowel disease, functional abnormality of the liver or liver disease, trauma or surgery within the prior 3-months, having received a blood transfusion, or malignant tumors were excluded because such factors could affect ET-1 levels [2].

Blood was collected $(5 \mathrm{~mL})$ from the forearm by using serum separation tubes (SST), was allowed to stand for 30 minutes at room temperature, and afterwards was centrifuged for 15 minutes at $1,000 \mathrm{G}$. The resulting serum was separated with SSTs, and the experiment proceeded. No hemolyzed serum or lipemic serum was used. The QuantiGlo ${ }^{\circledR}$ Human ET-1 immunoassay kit (R \& D System, Minneapolis, MN, USA) was used for quantitative analysis of ET-1. Contained in the kit were an ET-1 microplate, an ET-1 conjugate, an ET-1 standard, an assay diluent RD1-19, a calibrator diluent RD5-13, a wash buffer concentrate, Glo Reagent A, Glo Reagent B, and a plate cover. Preparatory steps taken for the experiment included the following: First, $100 \mathrm{~mL}$ of the wash buffer concentrate contained in the reagents was diluted 10 -fold by using distilled water (Type-1), and was prepared with a final volume of 1,000 mL. Second, $4 \mathrm{~mL}$ of Glo Reagent A and $8 \mathrm{~mL}$ of Glo Reagent $B$ were prepared 15 minutes before use and were then set aside and stabilized. They were stored, using the reagents prepared 4 hours before, in a darkroom (temperature, $18-24^{\circ} \mathrm{C}$ ). Since 100 $\mu \mathrm{L}$ of Glo Reagent is needed per the standard and the sample quantities, its quantity was adjusted according to the number of tests. Third, $1.0 \mathrm{~mL}$ of distilled water was added to the standard $(2.5 \mathrm{ng})$ by using a vortex, and it needed to be stabilized for at least 15 minutes. Fourth, $900 \mu \mathrm{L}$ of the calibrator diluent RD5-13 was moved to a tube labeled $250 \mathrm{pg} / \mathrm{mL}$ by using a pipette, the prepared standard was moved into a 2,500 pg/mL labeled tube, and $100 \mu \mathrm{L}$ was

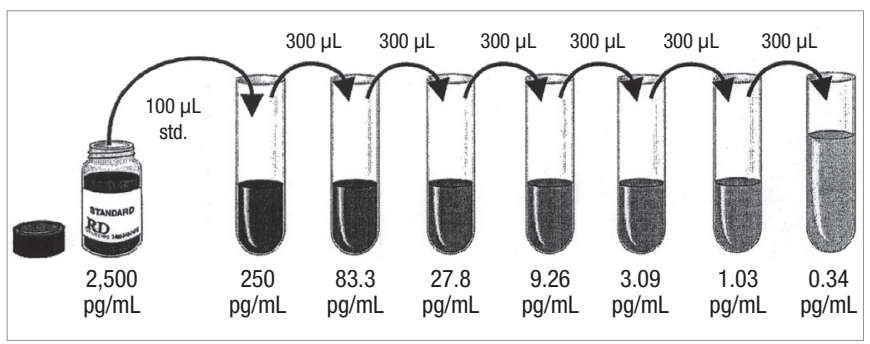

Fig. 1. Method for making standard diluent solutions. transferred into a $250 \mathrm{pg} / \mathrm{mL}$ labeled tube by using a pipette. Then, they were mixed well using a vortex. Into each of the remaining labeled tubes, $600 \mu \mathrm{L}$ of calibrator diluent RD5-13 was divided, and from a $250-\mathrm{pg} / \mathrm{mL}$ standard, $300 \mu \mathrm{L}$ with a pipette $250,83.3$, $27.8,9.26,3.09,1.03,0.34 \mathrm{pg} / \mathrm{mL}$ was prepared using a step dilution method and set aside. As shown in the Fig. 1, a dilute solution for the standards is created. The solution in each tube must be mixed completely and the pipettes must not be reused.

Once all the preparatory steps had been completed, all reagents, serum samples, and standards were prepared at room temperature, and the following experimental steps were conducted: 1) prepare reagents, samples, and standards; 2) add $100 \mu \mathrm{L}$ of assay diluents to each well; 3) add $100 \mu \mathrm{L}$ of standard, control or sample to each well and incubate 1.5 hours on the shaker at room temperature; 4) aspirate and wash 4 times; 5) add $200 \mu \mathrm{L}$ of conjugate to each well, incubate 3 hours on the shaker at room temperature, and prepare working Glo Reagent; 6) aspirate and wash 4 times; 7) add $100 \mu \mathrm{L}$ of working reagent to each well and incubate for 5-20 minutes on the bench-top while protecting from light; 8) determine the RLU of each well by using a luminometer (DML $2000^{\circledR}$, Hoil Biomed, Seoul, Korea). By noting the measured values, we compared the patients in the anal fissure group with the patients in the control group to see if differences in the measured values of ET-1 existed. Statistical analyses were conducted using the SPSS ver. 12.0 (SPSS Inc., Chicago, IL, USA), and for continuous variables, the Student's $\mathrm{t}$-test was used for comparative analyses. Statistical significance was defined as $\mathrm{P}<0.05$ at the $95 \%$ confidence level.

\section{RESULTS}

Among the total 90 patients, there were 38 males and 52 females, and their average age was 36.8 years (Table 1). The results of the experiment showed ET-1 levels of $1.21 \pm 0.44 \mathrm{pg} / \mathrm{mL}$ (range, 0.66 to $2.25 \mathrm{pg} / \mathrm{mL}$ ) for group $1,1.46 \pm 0.83 \mathrm{pg} / \mathrm{mL}$ (range, 0.6 to 3.69 $\mathrm{pg} / \mathrm{mL}$ ) for Group 2, $1.20 \pm 0.56 \mathrm{pg} / \mathrm{mL}$ (range, 0.58 to $2.68 \mathrm{pg} / \mathrm{mL}$ ) $(\mathrm{P}=0.14)$.

\section{DISCUSSION}

Anal fissure is one of the most frequently-occurring anal diseases. Acute anal fissure has a tendency to be cured within 1-2 weeks;

Table 1. Characteristics of patients and the results of Endothelin-1 (ET-1) for each group

\begin{tabular}{|c|c|c|c|c|}
\hline & Control & Fissure & Hemorrhoids & \\
\hline$M / F$ & $13 / 17$ & $14 / 16$ & $11 / 19$ & \\
\hline \multirow[t]{2}{*}{ Age (yr) } & $33.73 \pm 13.40$ & $33.37 \pm 13.19$ & $43.30 \pm 10.46$ & \\
\hline & $(20-57)$ & (16-63) & (22-61) & \\
\hline ET-1 (pg/mL) & $1.21 \pm 0.44$ & $1.46 \pm 0.83$ & $1.20 \pm 0.56$ & $P=0.14$ \\
\hline
\end{tabular}

Values are presented as mean \pm standard deviation (range). 
however, chronic anal fissure can last a long time, and it can recur. Chronic anal fissure is generally defined as a fissure having a history of more than 6-8 weeks, not responding to conservative therapy, having an ulcer base with fibers of the internal sphincter exposed, and displaying one of these three abnormalities: indurated edge, thickened papilla above and below the ulcer, or sentinel pile [1]. In this study, as well, the above criteria were used for selecting chronic anal fissure patients.

Due to the infectious process of the anal tissues, collagenolytic enzymes are produced, which reduces the tensile strength of anal tissue and makes the tissue susceptible to damage from even a small stimulus [6]. Therefore, when a hard stool passes through an anal canal that is infected, this can cause damage to the anal skin. In these patients, the pressure in the internal anal sphincter generally appears elevated. However, it is not clear as to whether the elevated pressure is the cause of the anal fissure or the result of the anal fissure. If the pressure in the internal anal sphincter continues to rise, this reduces the blood flow to this region and can cause chronicity of the anal fissure [2]. However, even without a rise of anal pressure, sometimes an anal fissure can occur and can heal naturally [7].

According to studies, an anal fissure can occur due to a localized ischemic process [8]. As in other organs, ischemic damage refers to the production of activated substances resulting from damage to the endothelium of a blood vessel [4]. The endothelium of a blood vessel is a confluent monolayer of thin, flattened, rhomboid-shaped cells lining the intimal surface of all blood vessels. It not only acts simply as a passive barrier to transvascular diffusion by being located between the blood flow and tissues but also plays the role of the largest endocrine organ in the body [3,4]. Normal endothelial cells serve to maintain the balance between growth promotion and inhibition, vasoconstriction and vasodilation, blood cell adherence and non-adherence, and anticoagulation and pro-coagulation [4]. The environmental effects that stimulate endothelial cells are bacterial or viral infections, hypoxia, physical force (shear stress), increased blood pressure applied to all layers of the blood vessel, smoking and hyperlipidemia [5]. Endothelial cells, by detecting these physical, chemical, humoral or environmental stimuli, transform blood vessels due to the pathological changes in the structure or function; the endothelial cells also play a critical role in maintaining homeostasis by generating and secreting various activated substances [4]. Among these substances, ET-1, first discovered by Yanagisawa et al. [9] in 1988, is a 21-amino-acid peptide and serves as a very strong, long-lasting vasoconstrictor. There are three isoforms, ET-1, ET-2, and ET-3, in the endothelin family; ET-1 is the major form and it, through the receptors (ETA) in the vascular smooth muscle, functions locally or systemically in a paracrine or an autocrine form $[3,4,9,10]$. Thus, it induces abnormal manifestations, such as vasoconstriction, vascular spasms, vascular hypertrophy, etc. [5]; although with limited data, evidence exists that ET-1 plays some role in the clinical manifestation of vasculitis [11]. If ET-1 is generated due to damage in or activation of the endothelium of a blood vessel, then suppression of endothelial nitric- oxide generation, hyperactive production of fibrous tissues, activation of chemotaxis of leukocytes and inflammation due to cytokines such as interleukin- 6 can be induced [4].

Under the assumption that the chronicity of an anal fissure can persist due to changes causing the anal pressure to elevate and causing ischemia to accelerate, this study was conducted. In the selection of subject patients, patients with various cardiovascular disease conditions [2] that could raise the level of ET-1 were excluded. One group consisted of normal patients without anal diseases such as anal fissure, hemorrhoids, etc. A second group consisted of anal fissure patients who met the chronic anal fissure condition [1], and a third group consisted of hemorrhoid patients who were over 3rd degree in the Goligher classification. The ET-1 levels in the serum of the patients in these groups were compared and analyzed. Although the normal group and the group of anal fissure patients did not show any difference in terms of the age distribution, the group of hemorrhoid patients showed a difference in age compared to the other groups because that group included only patients with over a 3rd degree Goligher classification. However, this difference in age did not affect the ET-1 levels. The average ET-1 levels were $1.21 \mathrm{pg} / \mathrm{mL}$ for the normal group, $1.46 \mathrm{pg} / \mathrm{mL}$ for the group of anal fissure patients and $1.20 \mathrm{pg} / \mathrm{mL}$ for the group of hemorrhoid patients. Although the group of anal fissure patients showed higher ET-1 levels than the other groups, there was no statistical significance $(P=0.14)$. Currently, in terms of the authors' hypothesis, the experimental results from the beginning stage of this study have not shown statistically significant levels of association between ET-1 and chronicity of anal fissure; however, statistical analyses of further studies with a greater number of subject patients is deemed to be necessary. In addition, whether ET- 1 can be a cause for anal fissure, whether ET- 1 can be a causal factor that perpetuates the chronicity of anal fissure, or, if it is indeed a causal factor, whether inhibiting the generation of ET-1 or blocking its receptors (ETA) $[4,10]$ will enable treatment of chronic anal fissure are points of interest that warrant additional study in the future.

Although the serum ET-1 levels of the chronic anal fissure patient group appear elevated compared to those of the normal group or the hemorrhoid patient group, this difference has no statistical significance. However, continuing studies in the future to establish whether an association exists between ET-1 and the chronicity of anal fissure are deemed to be necessary.

\section{CONFLICT OF INTEREST}

No potential conflict of interest relevant to this article was reported.

\section{REFERENCES}

1. Ayantunde AA, Debrah SA. Current concepts in anal fissures. World J Surg 2006;30:2246-60.

2. Maria G, Brisinda D, Ruggieri MP, Civello IM, Brisinda G. Identification of anti-endothelial cell antibodies in patients with chronic 


\section{Coloproctology cheong Ho Lim, et al.}

anal fissure. Surgery 1999;126:535-40.

3. Griffith TM, Edwards DH, Davies RL, Harrison TJ, Evans KT. EDRF coordinates the behaviour of vascular resistance vessels. Nature 1987;329:442-5.

4. Davies MG, Hagen PO. The vascular endothelium: a new horizon. Ann Surg 1993;218:593-609.

5. Abraham D, Distler O. How does endothelial cell injury start? The role of endothelin in systemic sclerosis. Arthritis Res Ther 2007;9 Suppl 2:S2.

6. Oh C, Divino CM, Steinhagen RM. Anal fissure: 20-year experience. Dis Colon Rectum 1995;38:378-82.

7. Gibbons CP, Read NW. Anal hypertonia in fissures: cause or effect?
Br J Surg 1986;73:443-5.

8. Schouten WR, Briel JW, Auwerda JJ, De Graaf EJ. Ischaemic nature of anal fissure. Br J Surg 1996;83:63-5.

9. Yanagisawa M, Inoue A, Ishikawa T, Kasuya Y, Kimura S, Kumagaye $\mathrm{S}$, et al. Primary structure, synthesis, and biological activity of rat endothelin, an endothelium-derived vasoconstrictor peptide. Proc Natl Acad Sci U S A 1988;85:6964-7.

10. Masaki T. Historical review: Endothelin. Trends Pharmacol Sci 2004;25:219-24.

11. Guillevin L, Dorner T. Vasculitis: mechanisms involved and clinical manifestations. Arthritis Res Ther 2007;9 Suppl 2:S9. 